\title{
Outcome of Neonates with Agenesis of Septum Pelluci- dum: A Retrospective Single Center Study
}

\author{
Yong Hee Kim ${ }^{1}$, Yeon Kyung Lee ${ }^{2}$, Sun Young Ko ${ }^{2}$, and Son Moon Shin ${ }^{1}$ \\ ${ }^{1}$ Department of Pediatrics, Cheil General Hospital \& Women's Healthcare Center, Seoul, Korea \\ ${ }^{2}$ Department of Pediatrics, College of Medicine, The Catholic University of Korea, Seoul, Korea
}

\section{ABSTRACT}

Purpose: Agenesis of the septum pellucidum (ASP) is a very rare disease that can be isolated or associated with other brain abnormalities. The neurological prognosis of isolated ASP remains controversial. The aim of this study was to evaluate the clinical outcome of neonates with ASP.

Methods: We retrospectively analyzed the medical records of 12 neonates with isolated ASP or ASP combined with other brain abnormalities who were born at Cheil General Hospital \& Women's Healthcare Center between January 2007 and December 2017.

Results: Of the 12 neonates, six were identified prenatally and six were identified postnatally. Isolated ASP was found in eight neonates; of these, four were detected antenatally. ASP associated with other brain abnormalities was found in four neonates. ASP was complete in nine neonates, including six with isolated ASP, and partial in three, including two with isolated ASP. Six of the eight neonates with isolated ASP had normal neurological development, except two who were lost to follow-up. Among the four neonates with other associated brain abnormalities, two had delayed motor development and a seizure, one had normal development, and one was lost to followup. In all neonates, ophthalmological examination revealed no optic nerve abnormalities.

Conclusion: Isolated ASP seems to have a good neurological prognosis without ocular problems. This result needs to be confirmed by larger prospective studies over a longer developmental timeline.

Key Words: Agenesis of septum pellucidum; Infant, newborn; Outcome

\section{서론}

투명중격 무형성증(agenesis of the septum pellucidum, ASP)은 매우 드물게 발견되는 뇌의 구 조적 이상으로, 대략 10 만 명당 2,3 명 정도의 비율로 발생한다고 알려져 있다 ${ }^{1)}$. 중추신경계의 발 달과정에서의 발생학적 기형으로 생기는 원발성인 경우가 대부분이지만, 예외적으로 수두증 등 에 의해 이차적으로 생길 수 있달. 원발성 ASP는 완전형과 부분형이 있을 수 있으며, ASP가 단
Received: 28 January 2019

Revised: 12 April 2019

Accepted: 22 April 2019

Correspondence to: Yeon Kyung Lee Department of Pediatrics, Uijeongbu St. Mary's Hospital, College of Medicine, The Catholic University of Korea, 271 Cheonbo-ro, Uijeongbu 11765, Korea

Tel: +82-31-820-3048

Fax: +82-31-821-3108

E-mail:ykleeped@hanmail.net https://orcid.org/0000-0001-8618-109X
Copyright(c)

By Korean Society of Neonatology. All right reserved.

This is an Open-Access article distributed under the terms of the Creative Commons Attribution Non-Commercial License (http://creativecommons.org/licenses/ by-nc/4.0), which permits unrestricted non-commercial use, distribution, and reproduction in any medium, provided the original work is properly cited. 
독으로 있는 경우와 다른 뇌기형이 동반되는 경우가 있다. 다른 뇌 기형이 동반된 $\mathrm{ASP}$ 는 동반된 뇌질환으로 인한 뇌전증, 발달지연, 정 신의학적인 문제 등이 발생할 수 있으며 ${ }^{3,4)} \mathrm{ASP}$ 가 단독으로 오는 경 우의 신경학적 예후에 대해서는 연구가 많지 않아 아직까지 이견이 있다 ${ }^{5)}$. 지금까지 ASP가 동반된 뇌기형의 산발적인 증례보고 ${ }^{6-8)}$ 및 단독 ASP에 대한 국외에서의 연구는 있었으나 ${ }^{9,10)}$, 국내에서는 연구 된 바가 없어 $\mathrm{ASP}$ 의 임상적 특징과 신경학적 예후에 대해 알아보고 자하였다.

\section{대상 및 방법}

2007년 1월부터 2017년 12월까지 본원에서 출생한 신생아 중에서 $\mathrm{ASP}$ 가 발견되었던 12 명을 대상으로 의무기록을 본원 임상연구윤리 위원회의 승인하에 후향적으로 연구하였고, 본 연구는 후향적 연구 로 연구자의 동의서 취득이 면제되었다(IRB No. CGHIRB-2018-23). $\mathrm{ASP}$ 는 두부 초음파 혹은 자기공명영상 (magnetic resonance imaging, MRI)을 통해 측뇌실 사이의 뇌량과 뇌궁(fornix) 사이를 연
결하는 투명중격이 없는 경우로 정의하였으며, 중격결손의 범위에 따라 완전, 부분적 ASP인 경우와, ASP가 단독으로 있는 경우, 다른 뇌기형이 동반된 경우에 대하여 조사하였다. 대상환자의 병록지 검 토를 통하여 분만력, 환자의 성별, 재태 기간, 출생체중, 임상증상, 영상의학검사 소견, 안과학적 검진 소견에 대하여 조사하였으며 퇴 원 후의 외래 기록을 조사하여 환자의 신경학적 발달 및 예후를 평가 하였다. 안과학적 검진은 출생 한 달 이내에 평가하였고, 이후 6개월 간격으로 정기적인 안과 검진을 시행하였다. 신경학적 발달 평가는 한국 영유아발달선별검사(Korean Developmental Screening Test for infants and children, K-DST)항목에 의거하여 절단점 '나' 이상에 해당하는 경우를 정상 발달로 판정하였다.

\section{결과}

\section{1. 임상적 특징}

본 연구 기간 동안 출생한 신생아는 총 69,346 명이었고, 이들 가운 데 ASP가 진단된 경우는 12 명이었으며, ASP가 단독으로 있는 경우

Table 1. Summary of Clinical Characteristics and Radiological Findings of Agenesis of the Septum Pellucidum

\begin{tabular}{|c|c|c|c|c|c|c|c|}
\hline $\begin{array}{l}\text { Case } \\
\text { no. }\end{array}$ & $\begin{array}{c}\text { GA } \\
\text { (wk) }\end{array}$ & $\begin{array}{l}\text { BW } \\
\text { (g) }\end{array}$ & Prenatal sonographic findings & Postnatal radiologic findings & $\begin{array}{c}\text { Type of } \\
\text { ASP }\end{array}$ & $\begin{array}{c}\text { Follow-up duration/ } \\
\text { neurological } \\
\text { outcome }\end{array}$ & $\begin{array}{l}\text { Ophthal- } \\
\text { mological } \\
\text { evaluation }\end{array}$ \\
\hline 1 & $32^{+2}$ & 1,220 & $\begin{array}{l}\text { ASP, small cyst in the posterior } \\
\text { fossa }\end{array}$ & Isolated ASP & Complete & $20 \mathrm{mo} /$ normal & Normal \\
\hline 2 & $39^{+3}$ & 2,830 & ASP & Isolated ASP & Complete & 2 wk/follow-up loss & Normal \\
\hline 3 & $40^{+4}$ & 2,920 & ASP & Isolated ASP & Complete & $4 \mathrm{yr} /$ normal & Normal \\
\hline 6 & $34^{+3}$ & 2,465 & Non-specific & Isolated ASP & Complete & $12 \mathrm{mo} /$ normal & Normal \\
\hline 7 & 35 & 1,950 & Non-specific & Isolated ASP & Partial & $5 \mathrm{yr} /$ normal & Normal \\
\hline 8 & $35^{+1}$ & 2,160 & Non-specific & Isolated ASP & Complete & $12 \mathrm{mo} / \mathrm{normal}$ & Normal \\
\hline 10 & $38^{+3}$ & 3,050 & $\begin{array}{l}\text { ASP with ventriculomegaly } \\
\text { (both } 11 \mathrm{~mm} \text { ) }\end{array}$ & $\begin{array}{l}\text { ASP with lateral ventriculomegaly (both } 13 \\
\mathrm{~mm} \text { ) }\end{array}$ & Complete & 2 wk/follow-up loss & Normal \\
\hline 11 & $39^{+3}$ & 3,235 & $\begin{array}{l}\text { ASP with ventriculomegaly } \\
\text { (Rt: } 16.5 \mathrm{~mm})\end{array}$ & $\begin{array}{l}\text { ASP with } \\
\text { 1. Asymmetric hypoplastic right optic nerve } \\
\text { 2. Ventriculomegaly (Rt: } 12 \mathrm{~mm} \text {; Lt: } 13 \mathrm{~mm} \text { ) }\end{array}$ & Complete & $4 \mathrm{yr} /$ normal & Normal \\
\hline 12 & $40^{+3}$ & 3,870 & $\begin{array}{l}\text { Ventriculomegaly } \\
\text { (Rt: } 13 ; \mathrm{Lt}: 14.6 \mathrm{~mm} \text { ) } \\
\text { R/O cerebellar vermis hypoplasia }\end{array}$ & $\begin{array}{l}\text { ASP with } \\
\text { 1. Diffuse dilatation of ventricular system } \\
\text { 2. Hypoplastic corpus callosum } \\
\text { 3. Hypoplastic cerebellum \& enlarged cisterna } \\
\text { magna }\end{array}$ & Partial & $\begin{array}{l}7 \text { mo/atypical } \\
\text { infantile spasm }\end{array}$ & Normal \\
\hline
\end{tabular}


가 8례, 다른 뇌기형이 동반된 ASP가 4례였다. 이들 중 산전 초음파 에서 $\mathrm{ASP}$ 가 발견되어 출생 후에 확인된 경우가 6례였으며, 산전 초 음파에서 발견되지 않았으나 출생 후에 인공호흡기 치료 등으로 인 하여 시행한 초음파에서 발견된 경우가 6례였으며, 단독 ASP 중에서 산전 또는 출생 후에 진단된 경우는 각각 4 례였다. 전체 12 례 중에서 남아가 7 명, 여아가 5명이었다. 평균 재태 연령은 $35^{+4} \pm 5^{+5}$ 주(범위, $23^{+5}-40^{+4}$ ) 였으며, 평균 출생체중은 $2,346 \pm 1,066 \mathrm{~g}$ (범위, 595-3,870)

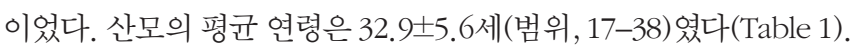

\section{2. 영상의학검사 소견}

전체 ASP 중에서 단독 $\mathrm{ASP}$ 의 경우는 8례(완전 6례, 부분 2례), 다 른 뇌기형이 동반된 경우는 4례(완전 3례, 부분 1례)였다. 완전 ASP 가 있는 경우는 9례로, 이 중에서 6례가 단독형이었으며(Figure 1), 부분적 $\mathrm{ASP}$ 는 3 례로 그 중 2례가 단독형이었다. 다른 뇌기형이 동반 된 경우로는 측뇌실 확장만 있는 경우 1 례, 제 3 뇌실, 측뇌실의 확장 과 뇌량의 저형성이 동반된 경우 1 례, 측뇌실 확장과 우측 시신경의 저형성이 동반된 경우 1 례, 측뇌실 확장, 뇌량의 저형성, 소뇌의 저 형성이 동반된 1례가 있었다(Figure 2).

\section{3. 조기 신경학적 발달 및 예후 평가}

단독 ASP 8례 중 6례에서의 추적 관찰 기간은 12 개월에서 6 세까 지였으며, 모두 정상적인 신경학적 발달을 보였으며, 안과적으로 시
신경 이상 및 내분비적 이상소견은 없었다. 나머지 2례에서 1례는 출생체중 $620 \mathrm{~g}$ 의 초미숙아로 괴사성 장염과 반복되는 패혈증에 의 해 사망하였으며, 다른 1 례는 추적 관찰이 이루어지지 않았다. 다른 뇌기형이 동반된 4 례 중 추적 관찰이 가능했던 환아는 3 례로 제 3 뇌 실, 측뇌실의 확장과 뇌량의 저형성이 동반된 1 례의 환아에서는 전 반적인 운동 발달 영역에서 지연을 보였으며, 안과학적 검진결과 근 시를 보였다. 측뇌실 확장, 뇌량 및 소뇌의 저형성이 동반된 1 례의 환아는 정상적인 신경학적 발달을 보였으나 7개월 경부터 비전형적 인 영아 연축(atypical infantile spasm)으로 항경련제를 복용 중이다. 이외에 측뇌실 확장과 시신경의 저형 성을 보인 1례는 정상적인 신경 학적 발달을 보였다(Table 1).

\section{고찰}

투명중격은 측뇌실 사이에 뇌량과 뇌궁 사이를 연결하는 투명한 판상형 구조물로서, 뇌실 쪽으로는 뇌실막(ependyma)을 따라서 위 치하고 폭은 1.5-3.0 mm에 달하며, 아교세포(glial cell), 신경세포 (neuron), 섬유속(fiber bundle), 맥락총 정맥(choroid plexus vein) 과 연결되는 정맥으로 구성되어 있으며, 발생학적으로 10-12주경에 형성되기 시작하여 17 주경이 되면 완성된다 ${ }^{2)}$. 투명중격은 해부학적 및 기능적으로 해마(hippocampus)와 시상하부(hypothalamus)를
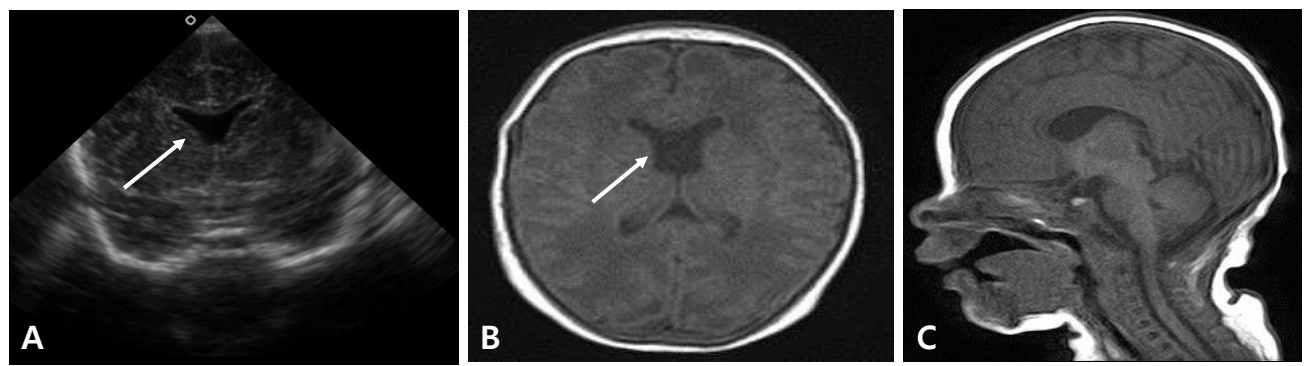

Figure 1. Cranial ultrasonography (A) and magnetic resonance images (B, C) showing isolated complete agenesis of the septum pellucidum (arrows) in case 6.
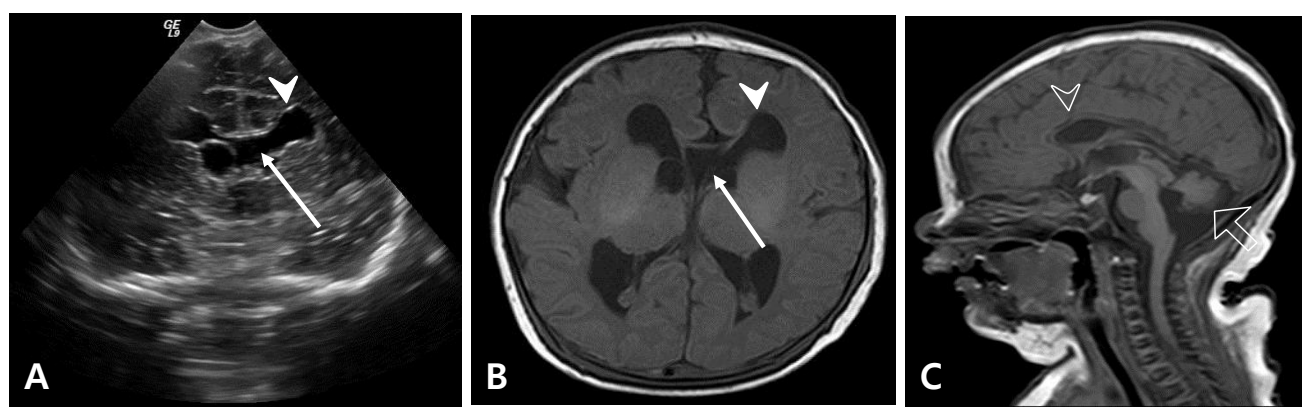

Figure 2. Cranial ultrasonography (A) and magnetic resonance images (B, C) showing partial agenesis of the septum pellucidum (arrows) with ventriculomegaly (arrowheads), hypoplastic corpus callosum (empty arrowhead), hypoplastic cerebellar vermis, and enlarged cisterna magna (empty arrow) in case 12 . 
연결하는 중계소로서, 기능은 정확하게 알려져 있지 않으나 대뇌 변 연계(limbic system)를 구성하는 시상하부와 뇌하수체를 연결하기 때문에 감정 반응에 관여하는 것으로 생각된다 ${ }^{11)}$. 따라서 이러한 중 격과 변연계 사이의 연결에 영향을 미치게 되는 투명중격의 형성장 애가 집중력 및 정신행동 장애를 유발하는 것으로 추정하고 있다 ${ }^{12)}$.

$\mathrm{ASP}$ 는 매우 드문 질환으로, 전뇌(forebrain)의 발달장애(maldevelopment)로 인해 생기는 선천적인 경우가 대부분이며, 중격결손 의 범위에 따라 완전, 부분적 ASP로 구분되고, 두부 초음파, 컴퓨터 단층촬영, MRI가 진단을 위하여 사용된다. 최근 산전 초음파 및 영 상의학검사의 발달과 확대로 $\mathrm{ASP}$ 의 진단이 점차 증가할 것으로 생 각되며, 이에 대한 임상적 중요성에 따른 적절한 평가가 필요하다. 또한 ASP가 단독으로 있을 수도 있지만 다른 뇌기형이 동반되는 경 우들이 있을 수 있어, ASP가 있을 경우 다른 뇌기형을 발견하기 위한 중요한 지표로서의 의미를 가진다. ASP와 동반된 뇌기형으로는 뇌 갈림증(schizencephaly), 완전전뇌증(holoprosencephaly), 중격 시 신경 형성이상(septo-optic dysplasia, SOD), 뇌량(corpus callosum) 의 무형성, 뇌실 확장증, 기저 뇌류(basilar encephalocele), 공뇌증 (porencephaly), 무뇌수두증(hydraencephaly) 등이 있을 수 있다,34) Belhocine 등 $^{13)}$ 에 의하면 ASP가 단독으로 있는 경우보다 위와 같은 뇌기형이 동반된 ASP가 더 많다고 하였으며, Barkovich와 Norman ${ }^{11}$ 은 단독 ASP는 있을 수 없다고도 하였다. 그러나 본 연구에서는 ASP 12 명 중 단독형이 8 명으로 다른 뇌기형이 동반된 경우에 비해 더 많 았다. 다른 뇌기형이 동반된 ASP에서는 연관된 뇌질환들이 신경학 적 예후에 영향을 주게 되어 정신지체, 뇌전증, 운동 발달 지연, 그 리고 주의력 결핍장애, 자폐증과 같은 행동장애 등이 있을 수 있다 ${ }^{3,4,13)}$. 본 연구에서 ASP와 동반된 뇌기형은 뇌량 저형성, 뇌실 확장 증, 시신경저형성, 소뇌 형성이상 등이 있었다. 뇌량 저형성과 뇌실 의 확장이 동반된 환아(증례 9)에서는 운동영역의 전반적인 발달 지 연이 있었으나 이는 ASP와의 연관성보다는 23 주로 태어난 초미숙아 에 의한 영향인 것으로 생각된다. 측뇌실 확장, 뇌량 및 소뇌의 저형 성이 동반된 경우(증례 12)에서는 7개월경까지 정상 발달을 보였으 나 이후 영아연축이 있어 항경련제를 지속적으로 복용 중이다. 그리 고 MRI에서 우측 시신경 저형성이 의심되고 측뇌실 확장이 동반된 경우(증례 11)에서는 정상 발달을 보였고 안과학적 검진에서 시신경 문제는 없는 것으로 판명되었다.

단독 ASP의 신경학적 예후에 대해서는 연구자마다 이견이 있다. Belhocine 등 ${ }^{13)}$ 에 따르면 ASP 34명 중 단독 ASP는 6명이 있었고, 이 들 중 3명에서 뇌전증 및 정신운동학적 발달 지연을 보였다. Damaj 등 ${ }^{5}$ 의 연구에서는 단독 ASP 17 명 중에서 14 명이 정상 신경학적 발 달을 보였고, 3 명에서 언어 발달 지연 및 정신의학적 문제가 있었으 며, Garcia-Arezza 등 ${ }^{10}$ 에 의한 단독 ASP의 증례 보고에서는 양호한 신경학적 예후를 보였다. 본 연구에서는 단독 ASP 8명 중에서 추적 관찰이 가능하였던 6 명이 정상적인 신경학적 발달을 보였다.
또한 단독 ASP에서 시신경 형성이상이 가려질 수 있어 $\mathrm{SOD}$ 를 놓 칠 수가 있기에 $\mathrm{SOD}$ 의 동반 여부가 예후에 영향을 주게 된다. 특히, 산전에는 다른 뇌기형이 동반되지 않은 ASP가 단독으로 발견되는 경우에 시신경과 뇌하수체 이상에 대한 평가가 쉽지 않아 SOD를 배 제하기가 어렵다. SOD는 ASP와 함께 한쪽 또는 양쪽의 시신경의 저 형성 또는 뇌하수체의 내분비 이상을 동반하는 경우로, 가장 흔하 게 안과적 문제들이 발생하며 60\%-90\%에서 시력감소 또는 실명까 지 다양한 형태의 안과적 문제가 있을 수 있다 ${ }^{14-16)}$. Barkovich 등 ${ }^{17)}$ 은 SOD 환자에서 시행한 MRI의 $50 \%$ 정도에서는 시신경이 정상으 로 보일 수 있기 때문에, MRI만으로는 시력장애를 완전히 배제할 수 없다고 보고하였다. 따라서 단독 ASP일지라도 정기적인 안과학적 검진이 중요하다. 또한 MRI에서 뇌하수체가 정상으로 보이더라도 내분비적인 문제가 있는 경우가 있고, 뇌하수체가 비정상으로 보이 는 경우라도 내분비적 문제가 없을 수도 있다 ${ }^{18)}$. 최근 Vawter-Lee 등 ${ }^{9)}$ 의 연구에서는 단독형 ASP 8 명 중 1 명에서 부신기능저하증을 발견 하였으며, 갑상선기능저하증과 부신기능저하증의 경우에는 심각한 결과를 초래할 수 있기에 이에 대한 뇌하수체 기능 평가가 필요하다 고 하였으나, Garcia-Filion 등 ${ }^{19}$ 의 연구에서는 단독형 ASP, SOD가 뇌하수체기능저하증과 연관이 없는 것으로 보고하였다.

본 연구 결과에서는 모든 ASP의 안과학적 검진 결과에서 시신경 의 문제는 없었으며 내분비적 기능검사에서 생후 1 주일 이내에 시행 한 갑상선 기능은 정상이었고 그 외의 뇌하수체기능저하증에 대한 평가는 이루어지지 않았으나, 그로 인한 임상증상은 없었다. 또한 단독 ASP의 추적 관찰이 가능했던 모든 증례에서 정상적인 신경학 적 발달을 보였고, 뇌전증 등의 신경증상을 보이는 경우는 없었다. 기존의 연구에 따르면 단독 ASP에서는 완전형이 많고 부분형인 경 우에는 다른 뇌기형이 동반된 경우가 많다고 보고하였으나 ${ }^{15,20)}$, 본 연구에서는 단독 및 다른 뇌기형이 동반된 ASP 모두에서 완전형이 많았다. 하지만 뇌기형이 동반된 수가 적어 이에 대한 추가적인 연 구가 필요할 것으로 생각된다.

$\mathrm{ASP}$ 를 진단하기 위해서는 산전 또는 출생 후 두부 초음파나 MRI 를 시행하여야 한다. 본 연구에서 출생 후 두부 초음파는 전례에서 생후 1 주일 이내에 시행하였으며, MRI는 12 례의 ASP 환자 중 8 례에 서 생후 1 개월 이내에 시행하였다. 증례 4 에서는 산전에 MRI를 시행 하였기에 출생 후에 시행하지 않았고, 증례 5의 경우 패혈증으로 사 망하여 MRI를 시행하지 못하였다. 본 연구에서 ASP가 확인된 12 명 은 모두 출생 전에 산전 초음파가 이루어졌으나 산전에서 발견된 경 우는 단독형 ASP 4명과 다른 뇌기형을 동반한 ASP 2명으로 총 6명이 었고, 출생 후에 발견된 경우가 6명이었다. 따라서, 산전 초음파에서 발견하지 못하는 경우와 출생한 모든 아이에서 두부 초음파가 시행 되지 않았기 때문에 실제 ASP의 환자 수는 더 많을 것으로 예측된다.

결론적으로 본 연구 결과에서 $\mathrm{ASP}$ 는 단독형과 완전형이 많았으 며, 단독 ASP는 신경학적, 안과적으로 양호한 예후를 보였다. 이는 
단독 ASP에 대한 국내 연구가 미미한 상태에서 ASP가 발견된 아기 의 부모 상담을 위한 참고자료로 이용될 수 있을 것으로 생각된다. 하지만 본 연구의 제한점으로 대상 환아 수가 적고, 내분비적 평가의 제한성과 학습장애 및 정신행동적인 문제들이 나타나는 연령은 늦 은 경우가 많기 때문에 이를 평가하기에는 추적 관찰 기간이 짧았던 점을 들 수 있다. 따라서 이와 같은 점들을 보완한 전향적인 연구 및 장기적인 추적 관찰이 필요할 것으로 생각된다.

\section{이해관계}

본 저자는 이 논문과 관련된 이해관계가 없음.

\section{REFERENCES}

1. Barkovich AJ, Norman D. Absence of the septum pellucidum: a useful sign in the diagnosis of congenital brain malformations AJR Am J Roentgenol 1989;152:353-60.

2. Sarwar M. The septum pellucidum: normal and abnormal. AJNR Am J Neuroradiol 1989;10:989-1005.

3. Schaefer GB, Bodensteiner JB, Thompson JN Jr. Subtle anomalies of the septum pellucidum and neurodevelopmental deficits. Dev Med Child Neurol 1994;36:554-9.

4. Malinger G, Lev D, Kidron D, Heredia F, Hershkovitz R, LermanSagie T. Differential diagnosis in fetuses with absent septum pellucidum. Ultrasound Obstet Gynecol 2005;25:42-9.

5. Damaj L, Bruneau B, Ferry M, Moutard ML, Garel C, Odent S, et al. Pediatric outcome of children with the prenatal diagnosis of isolated septal agenesis. Prenat Diagn 2010;30:1143-50.

6. Kwak JG, Jung S, Kwon SB, Hwang SH, Lee BC, Kwon KH. A patient with septo-optic dysplasia plus. J Neurol Sci 2008;264: 166-7.

7. Kim JH, Lee KB, Lee JH, Nam SM, Lee KW, Hwang EG, et al. A case of septo-optic dysplasia resulting in central diabetes insipidus and nonobstructive bilateral hydronephrosis. Korean J Med 2014;87:209-14.

8. Chun YK, Kim HS, Hong SR, Chi JG. Absence of the septum pellucidum associated with a midline fornical nodule and ventriculomegaly: a report of two cases. J Korean Med Sci 2010;
25:970-3.

9. Vawter-Lee MM, Wasserman H, Thomas CW, Nichols B, Nagaraj UD, Schapiro M, et al. Outcome of isolated absent septum pellucidum diagnosed by fetal magnetic resonance imaging (MRI) scan. J Child Neurol 2018;33:693-9.

10. Garcia-Arreza A, Garcia-Diaz L, Fajardo M, Carreto P, Antinolo G. Isolated absence of septum pellucidum: prenatal diagnosis and outcome. Fetal Diagn Ther 2013;33:130-2.

11. Aldur MM, Gurcan F, Basar R, Aksit MD. Frequency of septum pellucidum anomalies in non-psychotic population: a magnetic resonance imaging study. Surg Radiol Anat 1999;21:119-23.

12. Wolf SS, Hyde TM, Weinberger DR. Malformations of the sep tum pellucidum: two distinctive cases in association with schizophrenia. J Psychiatry Neurosci 1994;19:140-4.

13. Belhocine O, Andre C, Kalifa G, Adamsbaum C. Does asymp tomatic septal agenesis exist? A review of 34 cases. Pediatr Radiol 2005;35:410-8.

14. Hellstrom A, Aronsson M, Axelson C, Kyllerman M, Kopp S, Steffenburg S, et al. Children with septo-optic dysplasia: how to improve and sharpen the diagnosis. Horm Res 2000;53 Suppl 1:19-25.

15. Izenberg N, Rosenblum M, Parks JS. The endocrine spectrum of septo-optic dysplasia. Clin Pediatr (Phila) 1984;23:632-6.

16. Cameron FJ, Khadilkar VV, Stanhope R. Pituitary dysfunction, morbidity and mortality with congenital midline malformation of the cerebrum. Eur J Pediatr 1999;158:97-102.

17. Barkovich AJ, Fram EK, Norman D. Septo-optic dysplasia: MR imaging. Radiology 1989;171:189-92.

18. Birkebaek NH, Patel L, Wright NB, Grigg JR, Sinha S, Hall CM, et al. Optic nerve size evaluated by magnetic resonance imaging in children with optic nerve hypoplasia, multiple pituitary hormone deficiency, isolated growth hormone deficiency, and idiopathic short stature. J Pediatr 2004;145:536-41.

19. Garcia-Filion P, Almarzouki H, Fink C, Geffner M, Nelson M, Borchert M. Brain malformations do not predict hypopituitarism in young children with optic nerve hypoplasia. Horm Res Paediatr 2017;88:251-7.

20. Raybaud C, Girard N, Levrier O, Peretti-Viton P, Manera L, Farnarier P. Schizencephaly: correlation between the lobar topography of the cleft(s) and absence of the septum pellucidum. Childs Nerv Syst 2001;17:217-22. 